\title{
Brasil y la creación de revistas científicas fuera de los grandes centros: Revista Brasileira do Caribe
}

\author{
Olga Cabrera
}

\section{Revista Brasileira do Caribe}

Centro de Estudos do Caribe no Brasil, vol. XII, núm. 24, enero-junio, 2012, 582 pp.

\section{REVISTA BRASILEIRA DO CARIBE} Revista do Centro de Estudos do Caribe no Brasil

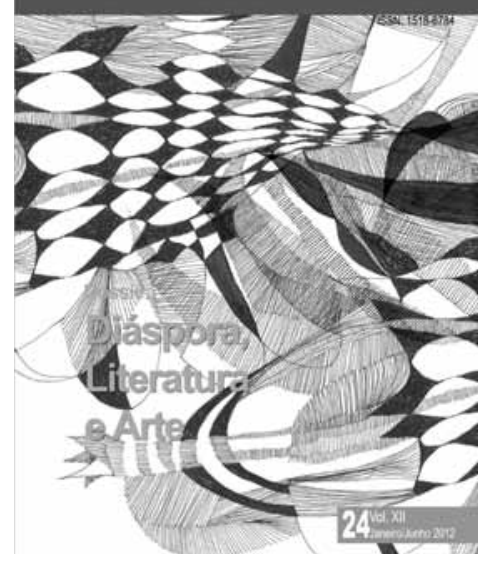

\section{INTRODUCCIÓN}

$\Lambda$ muchos les pareció un desatino el traslado de la Revista Brasileira do Caribe de Goiás - centro-oeste brasileño con altos indicadores en la economía, en la sociedad, en la educación, que lo equiparan con los estados del Sur y del Sudeste $-1{ }^{1}$ a Marañón —el estado

${ }^{1}$ La Revista estuvo un breve periodo en la Universidad de Brasilia (UnB).
Brazil and the Creation of Scientific Journals Outside the Great Centres: Revista Brasileira do Caribe

Olga Cabrera: Instituto de Estudios Socioambientales, Universidad Federal de Goiás, Goiás, Brasil olgarosacgarcia@gmail.com

Desacatos, núm. 42, mayo-agosto 2013, pp. 258-270 con el menor desarrollo humano del país y donde todos los indicadores, educación y salud, entre muchos otros, son los más bajos-. Sin embargo, quienes piensan así no saben u olvidan que la Revista se gestó en Goiás en 2000, cuando esos indicadores ni asomaban en el horizonte del estado. Además, los estudios del Caribe, que tanto éxito tuvieron en el contexto nacional, no hubieran podido crear un instituto o centro especializado integrado por investigadores, como señalaba su proyecto original cuando se fundó el Centro de Estudios del Caribe en Brasil (Cecab). Después de una reorganización, el Cecab se encuentra funcionando de nuevo, con la participación de profesores 
de historia y del Instituto de Estudios Socioambientales ${ }^{2}$ de la Universidad Federal de Goiás (UFG), y organiza su octava convocatoria para un Simposio internacional que será realizado en Goiânia, Goiás, en mayo de 2013. Algunos de los profesores y estudiantes que participamos en la construcción del Centro del Caribe y de la Revista previmos la imposibilidad de crear un instituto del Caribe en Goiás y decidimos fortalecer la posgraduación en historia para enfrentar algunos de sus vicios de origen - surgió en los inicios de la dictadura militar- que limitaban su desarrollo, como indicaban las bajas evaluaciones que la Coordinación de Perfeccionamiento de Personal de Nivel Superior (CAPES) recibió de manera consecutiva. Así nació el Programa Nacional de Cooperación Académica (Procad), en colaboración interuniversitaria con la CAPES, que sirvió para la creación de una propuesta original, apoyada por el posgrado en historia de Brasilia. Las bases teóricas del programa de doctorado se centraron en los postulados de los caribeños. No había tiempo para

\footnotetext{
${ }^{2}$ La autora del artículo, fundadora del Centro y de la Revista, está incorporada a este Instituto, aunque trabaja en la formación de un nuevo posgrado en la Amazonia Legal —en su entrada por la Bajada Occidental de Marañón- como invitada senior de la Coordinación de Perfeccionamiento de Personal de Nivel Superior (CAPES) en la Universidad Federal de Marañón.
}

pensar en un programa diferente y los conceptos utilizados en el área de concentración del proyecto de doctorado, concebido inicialmente para estudios del Caribe, pasaron a intentar el diálogo con las investigaciones anteriores de la maestría de historia de las sociedades agrarias - nombre adoptado desde su fundación en los años sesentay a abrir espacios más amplios desde el sertón, reservado a los antropólogos y menospreciado hasta entonces en el campo de la historia. Esa falta de interés en esta zona cercana explica la carencia de bases sólidas en los trabajos históricos desarrollados en Goiás para establecer conexiones con los estudios del Caribe.

A pesar de Guimarães Rosa, el sertón nunca podría transformarse en mar, por lo menos en la obra de la mayoría de los historiadores que estudiaron Goiás. Este gran novelista brasileño, lejos de nutrirse en la reproducción de los modelos nacidos en los grandes centros, buscó el camino de la creación en el contacto con las culturas de la región, en donde la historia, la filosofía, los valores, se gestaron en ausencia de modelos para imitar: eran hombres y mujeres, producto de múltiples mestizajes, y crearon lazos indisolubles de respeto, amistad y amor en la lucha por sobrevivir en un espacio violento, inhóspito y arisco. El sertón fue desestimado por el desarrollismo y las teorías de la historia cultural que modelaron las ideas sobre la modernidad en la historia de Goiás. Y aunque durante un breve periodo, que se correspondió con la democratización del país, los textos marxistas se apoyaron en los aspectos sociales del ámbito rural, estaban permeados por la idea de la modernidad y lanzaron al mismo saco a la burguesía rural y a los campesinos. Para los marxistas el futuro estaba en los desposeídos de la tierra, ahora transformados en clase social revolucionaria. Desde la academia, que ocupaba como propios los espacios universitarios en unas y otras posiciones, fueron exaltados los valores de la modernidad que colocaba en el otro extremo de la dicotomía a las poblaciones rurales como representativas del atraso: eran el pasado que tenía que superarse. Mas Brasil no es homogéneo, es uno y al mismo tiempo es múltiple. La Revista fomentó el estudio de esos varios "Brasiles" que podrían dialogar con la diversidad caribeña. Se aproximó al Nordeste en dos de los últimos congresos realizados por el Cecab, uno en Salvador de Bahía y otro en San Luis, Marañón. Ningún otro espacio pareció más adecuado para la continuación del debate que la Isla de San Luis, también conocida como la "Jamaica brasileña". El debate no se encerraba en la universidad ni en 
ningún espacio intelectual, corría por las calles, por los bares, se transformaba en la música y letra del reggae recreado por el pueblo en música propia para divertirse, pero también para protestar por las injusticias sociales.

\section{LA FUNDACIÓN DEL CENTRO DE ESTUDIOS DEL CARIBE Y DE LA REVISTA BRASILEIRA DO CARIBE}

La fundación del Cecab en 1999, con la participación de algunos estudiantes y profesores, responde a la carencia de instituciones en Brasil dedicadas a los estudios del Caribe y a la intención de crear un espacio de diálogo nacional e internacional para la Revista Brasileira do Caribe. Tenía entre sus tareas concentrar en sus simposios internacionales a un núcleo de estudiosos que contribuyeran con la Revista, que se publicaría al año siguiente y coincidiría con el Primer Simposio Internacional del Caribe. Así, el primer número de la Revista Brasileira do Caribe se publicó en diciembre de 2000. La Revista llegó al contexto goiano al hurgar sobre el "otro", oculto por ser negro o indio, silenciado, oscurecido, visible apenas en la tradición, en el folclore. Si algo destacó la Revista fue ese Brasil múltiple que podría establar diálogo con el Caribe negro, ausente también en los estudios latinoamericanos en Brasil, que negaban el Caribe y olvidaban que su perspectiva nació de la injusticia creada por las visiones jerárquicas establecidas sobre todo por Estados Unidos en el Continente Americano. Pero la Revista, que había sido fundada para incorporar a los estudios históricos brasileños la idea de historias interconectadas con otros pueblos, no encontró eco en el ambiente de la UFG, dado que en ese periodo la universalización de los estudios históricos estaba excluida. Para estos académicos apenas contaba la raíz europea en el estudio de los orígenes de Brasil. Por tanto, había que conocer muy bien los cambios ocurridos en Inglaterra con la Revolución Industrial, además de que no se mencionaban los acontecimientos africanos paralelos: el secuestro de pueblos, etnias y tribus, en su mayoría introducidos en Brasil —más de seis millones-, cuyos descendientes representan más de $40 \%$ de la población de Goiás.

La Revista es un lugar de diálogo interdisciplinario e intercultural, que ha mantenido el interés de proporcionar conocimientos sobre las teorías y los espacios culturales del Caribe en sus conexiones con el mundo atlántico y latinoamericano, en especial con Brasil. En ese sentido, los congresos organizados por el Cecab apoyaron a la Revista al reunir a investigadores del Caribe, África, América del Norte, Europa y
América del Sur en torno a temas como las conexiones caribeñas con el mundo, la discusión de los procesos formativos de identidades y las narrativas derivadas de los mitos, proverbios, relatos, músicas, danzas, performances y religión. Otros temas analizados en la Revista han sido las migraciones, las relaciones de género, las literaturas y músicas caribeñas, las transculturaciones entre las culturas africanas y europeas, las territorialidades, los efectos del turismo y los derechos humanos. Hasta entonces pocos especialistas en Brasil, con escasos y efímeros contactos, habían explorado algunos aspectos sobre el Caribe. Pero la Revista comenzó a tener presencia en otras partes del país: en Río de Janeiro, por medio de profesores de la Universidad Federal Fluminense que habían trabajado con la literatura en las islas de colonización francesa del Caribe — destaca Maria Bernadette Porto-; a través de otros docentes inquietos de Brasilia que percibieron que las teorías culturales podrían encontrar tierra firme en el Caribe para entender algunos aspectos de Brasil; Maria Tereza Negrão de Melo proyectó en sus trabajos la aproximación a Cuba y a Latinoamérica, en particular aquellos sobre el cine de Glauber Rocha; el profesor Jaime de Almeida, vinculado a la Asociación Nacional de 


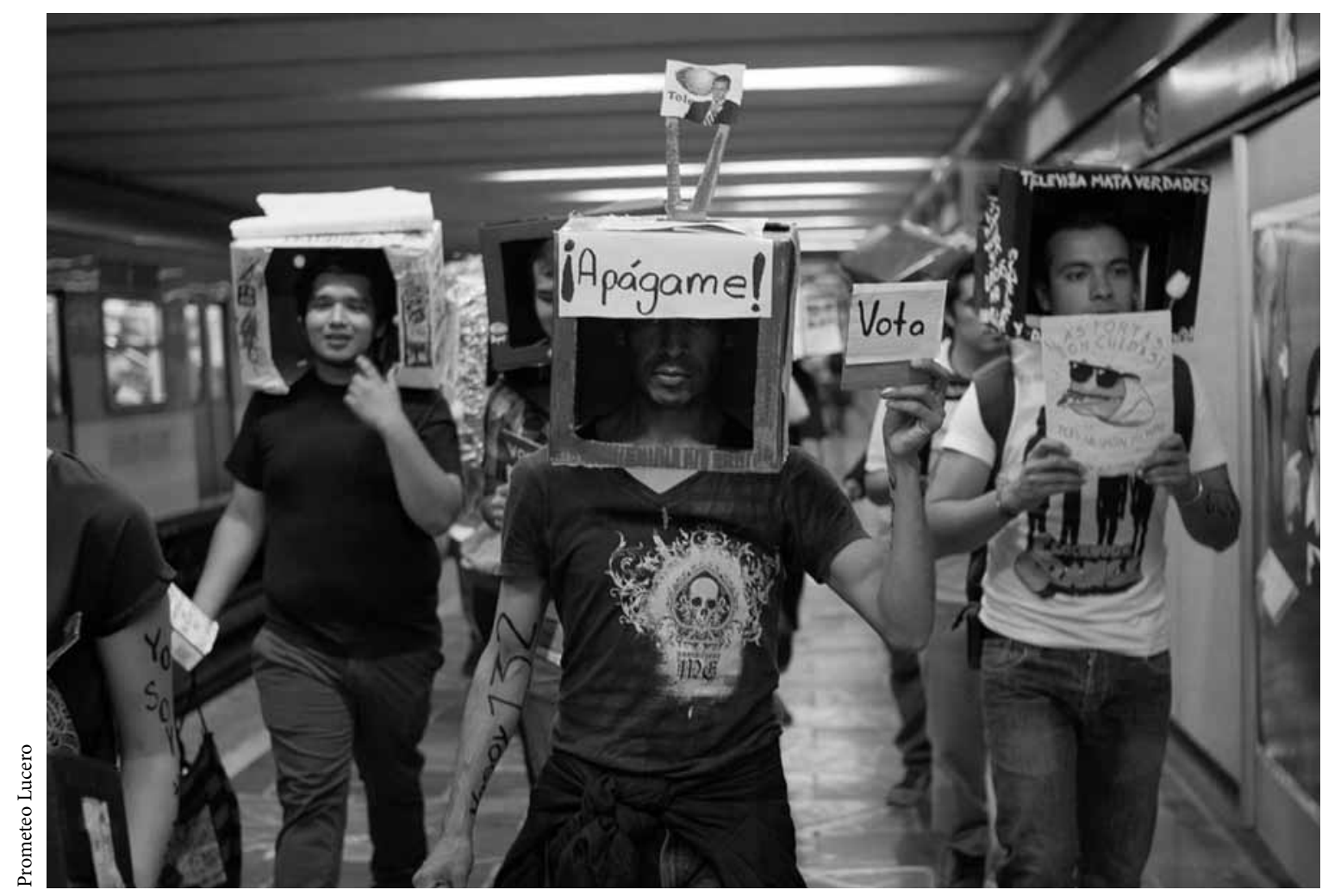

Performance de \#YoSoy132 en la ciudad de México, 13 de junio de 2012.

Profesores de Historia de Latinoamérica y del Caribe (ANPHLAC), encontró en la Revista la posibilidad de ampliar sus estudios encaminados hacia las efemérides en el Caribe y orientó algunas tesis en esa dirección.

Con el apoyo de la CAPEs se adquirieron libros, los estudiantes de posgrado hicieron viajes de estudio, se organizaron debates, cafés caribeños - estos últimos tuvieron su centro en la unB-y se publicaron libros en México y Brasil. Finalmente, el programa de doctorado en historia de la UFG, creado con el apoyo del programa de posgraduación en historia de la unB, fue aprobado. Los simposios internacionales del Cecab y la publicación de la Revista lograron incorporar a muchos estudiantes que valoraron otras perspectivas de estudio. Las conferencias, los debates, los minicursos, los talleres con profesores mexicanos, estadounidenses, ingleses, franceses, españoles, cubanos, puertorriqueños, jamaiquinos, haitianos, italianos, senegaleses, congoleños, nigerianos, del Caribe holandés, surinameses, trinitenses, colombianos, entre otros, contribuyeron a que estos jóvenes seleccionaran los estudios del Caribe. La Revista obtuvo mayor proyección internacional, mientras se extendía por todo Brasil: en Bahía predominaron los estudios que tenían como base la comparación con el Caribe colombiano - Joseania de Freitas- y con la música cubana -Carlos Moura-; en Marañón, Minas Gerais y Goiás surgían las investigaciones sobre los movimientos rastafari en Jamaica y los vínculos entre ésta y Marañón - Benedito da Silva, Maristane Rosa, Leonardo Vidigal y Danilo Rabelo-, en São Paulo, desde la Universidad 
Católica, se hicieron estudios comparativos entre los teatros negros cubano y brasileño bajo la dirección de Maria Antonieta Antonacci. Una nueva generación de estudiantes de los doctorados de Brasilia y Goiás, formados gracias al Procad y colaboradores de la Revista Brasileira do Caribe durante varios años, obtenían sus plazas como profesores en las universidades federales de todo el país: Amazonia, Tocantins, Pelotas —Rio Grande do Sul—, Pará, Goiás, Marañón, lo que provocó la extensión del Caribe por todo Brasil.

\section{EL ESPACIO NACIONAL \\ DE LA REVISTA}

En los estudios propiamente caribeños sobresalió el grupo de la Universidad Federal Fluminense de Río de Janeiro, porque reunió a profesores de varias partes del país en torno a la literatura del Caribe francés. Sin embargo, la mayoría de sus investigaciones no estableció relaciones con la historia y la literatura brasileñas. El contrasentido de que Brasil - un país con una dimensión continental, con una proyección política destacada en el Continente Americano y el segundo lugar del mundo en población negra- posea pocos especialistas en temas sobre el Caribe, aun 10 años después de la existencia del Centro y de la Revista, pienso, remite a su historia y al estado de las ciencias humanas y sociales en el país. ¿Cómo se explica la preeminencia de la representación de la identidad nacional entre académicos dedicados a los estudios sobre los afrobrasileños y los movimientos negros en Brasil? Aún hoy orientan sus enfoques hacia la genealogía y la historia africanas, los orígenes, mientras desconocen la simultaneidad de procesos entre Brasil y el Caribe. La ausencia de investigaciones y de autores negros caribeños en el espacio brasileño impide conocer los argumentos que éstos levantan contra la visión de las interpretaciones basadas en la raíz, la genealogía, al mismo tiempo que defienden las teorías basadas en las relaciones y los procesos de formación de identidades más que los resultados de éstos en identidades terminadas. Ese acercamiento al Caribe propiciaría una profundización de la historia y la cultura afrobrasileñas. El diálogo en lugares simultáneos significa abandonar la idea de fijar al sujeto a sus orígenes y verlo en el dinamismo de su continua formación en múltiples interrelaciones. Esa postura permite pensar en la simultaneidad de los procesos históricos. En este caso se trata de mover el diálogo de los sujetos con idéntica procedencia —étnica, país, pueblo, tribu, familia - a los fenómenos ocurridos en el barco negrero en el que se crearon vínculos de solidaridad durante el viaje y se recrearon las lenguas para entenderse - los denominados “carabelas", cuya amistad, gestada más allá de la etnia, muchas veces fue sellada con sangre en la plantación esclavista-. La formación de estos hombres, mujeres y hasta niños transcurrió en espacios/lugares diferentes y se vieron obligados a construir nuevos lazos que transcendieron las identidades originales.

En el Caribe donde desembarcaron muchos africanos —más de un millón en Cuba durante el siglo XIX - el ambiente no poseía la fauna salvaje de África, cuyos mejores ejemplares eran enfrentados por los jóvenes como pruebas de valentía cuando pasaban el periodo liminar de la niñez. La prueba que se les exigía ahora era la sumisión a otro hombre: el blanco. Sólo en los casos de grandes concentraciones de esclavos pudieron mantenerse las danzas colectivas, que fueron un medio de comunicación intercultural entre hombres y mujeres procedentes de diversos pueblos africanos. El estudio de procesos en lugares diferentes impide pensar los fenómenos a partir de su ontología, en su estatismo, terminados. Su ser, su esencia, es la cultura, dinámica: es el movimiento de un llegar a ser que nunca 
es, como subraya Mary Douglas, con su cultura en acción.

También debemos considerar que los estudios latinoamericanos, que en Brasil incluyen los estudios sobre el Caribe, han sido escasos, pero siempre tuvieron mayor presencia que los caribeños. Cuando se estudiaba algún país del Caribe era revestido de un latinoamericanismo por la supremacía filosófica occidental. Algunos investigadores de esa línea expresaron su reticencia a las conexiones entre las historias brasileña y caribeña. La subordinación teórica y metodológica a las visiones sobre Latinoamérica en Brasil oculta también al Caribe por no focalizar la relación entre la historia afroamericana y el colonialismo. ¿Estarán estas posiciones relacionadas con la invisibilidad de la historia afrobrasileña en los estudios latinoamericanos, en los que no es encarado uno de los más prolíficos y conspicuos temas del Caribe? A saber, la formación de sus sociedades a partir de las relaciones y colisiones entre inmigraciones voluntarias de colonizadores y familias europeas, y las inmigraciones forzadas africanas y asiáticas, con la explotación indígena en algunos de los casos. El alejamiento de Brasil respecto de Afroamérica - Caribe principalmente- puede responder a la subordinación de los estudios caribeños a los latinoamericanos, la cual revela que la vieja maniobra de la invisibilidad sobre la participación de los negros y sus culturas en la formación de Brasil puede recorrer otros caminos. El Caribe sólo obtiene visibilidad en Brasil desde su proyección como región geopolítica en las visiones imperiales o como frontera de la civilización en las interpretaciones que ligaban el atraso a la presencia de las poblaciones negras. La Revolución Cubana despertó algún interés y aun en sus manifestaciones políticas hay una carencia del Caribe en la historiografía, que se refleja en los libros de texto. Aunque tampoco está muy representada América Latina, sobresale el hecho de que es una historia que tuvo muchas conexiones en el siglo pasado - existieron hasta entre negreros brasileños y cubanos, sin las familias y etnias que fueron separadas y dejadas en uno u otro lugar no apenas durante el tráfico negrero, lo mismo que durante la ocupación de territorios brasileños por las potencias occidentales$\mathrm{y}$ ahora son historias paralelas, sincrónicas.

Ese movimiento estuvo presente también en la historiografía e incluso en los proyectos políticos latinoamericanos: Brasil quedó como una zona indefinida y a veces totalmente fuera de los ensayos en los que se estudiaba el conjunto de las culturas de la región. Las producciones brasileñas, a su vez, compartieron ese rasgo de incomunicación. Brasil se relacionó con la intelectualidad europea, sobre todo con la francesa, más que con sus vecinos hispánicos o de las islas y los territorios continentales fronterizos. La construcción del latinoamericanismo, como un contrasentido histórico, a pesar de legitimar la diferencia entre la América hispánica - menos en la portuguesa - y Estados Unidos, condujo a la subordinación del Caribe y de esta forma oscureció la historia y la cultura de las poblaciones negras en general. En Brasil durante el siglo XIx la construcción de la identidad nacional por las elites blancas, por su parte, desembocó en el ocultamiento de la diferencia bajo la fórmula primero del blanqueamiento y mascarada más tarde en el sincretismo. Otra forma de ocultamiento provino de la segregación de las poblaciones negras en los espacios marginales, tanto en las zonas rurales como en las ciudades, lo que contribuyó a su definición apenas social, porque de manera simultánea estos sectores de la población fueron empujados a los niveles más bajos de la pobreza. Los estudios latinoamericanos tienen que contribuir a iluminar esos espacios de contradicciones. No hay que olvidar que el país emerge como potencia y es 
necesario delimitar el Brasil colonialista del que se orienta por el respeto a la diferencia $\mathrm{y}$ a la igualdad de derechos.

\section{UN ESPACIO REGIONAL PARA LA REVISTA}

Estos debates y contextos explican la necesidad de ubicar la Revista en el espacio regional de Brasil más adecuado para el cumplimiento de su misión:

La Revista Brasileira do Caribe tiene como misión principal focalizar el estudio de las culturas afroamericanas en su relación con otras culturas y con sus matrices africanas. Esta misión se afirma en la comprensión del nexo que une a Brasil con el Caribe [...] El Caribe aporta un debate intelectual a los estudios afroamericanos, cuyo espacio de reflexión siempre ha sido transnacional, y una filosofía alternativa que permite pensar las culturas negras en la actualidad y su importancia en el proceso de formación social, cultural, histórica y también nacional (Revista Brasileira do Caribe, "Misión").

Brasil y el Caribe son representados como regiones de profundos intersticios culturales donde las manifestaciones de matriz africana y amerindia fueron ocultas, negadas, marcadas por el estigma del atraso y de la barbarie. África, a su vez, se presenta como una región ancestral de pueblos y etnias subalternas del Nuevo Mundo, como un lugar de tradiciones culturales estáticas y homogéneas, o de atraso y subdesarrollo, lo que oscurece las relaciones entre sus múltiples culturas. Las culturas negras y sus matrices africanas emergen cuando son removidas tanto las configuraciones intelectuales basadas en la dicotomía modernidad/tradición como las creadas en los rígidos marcos

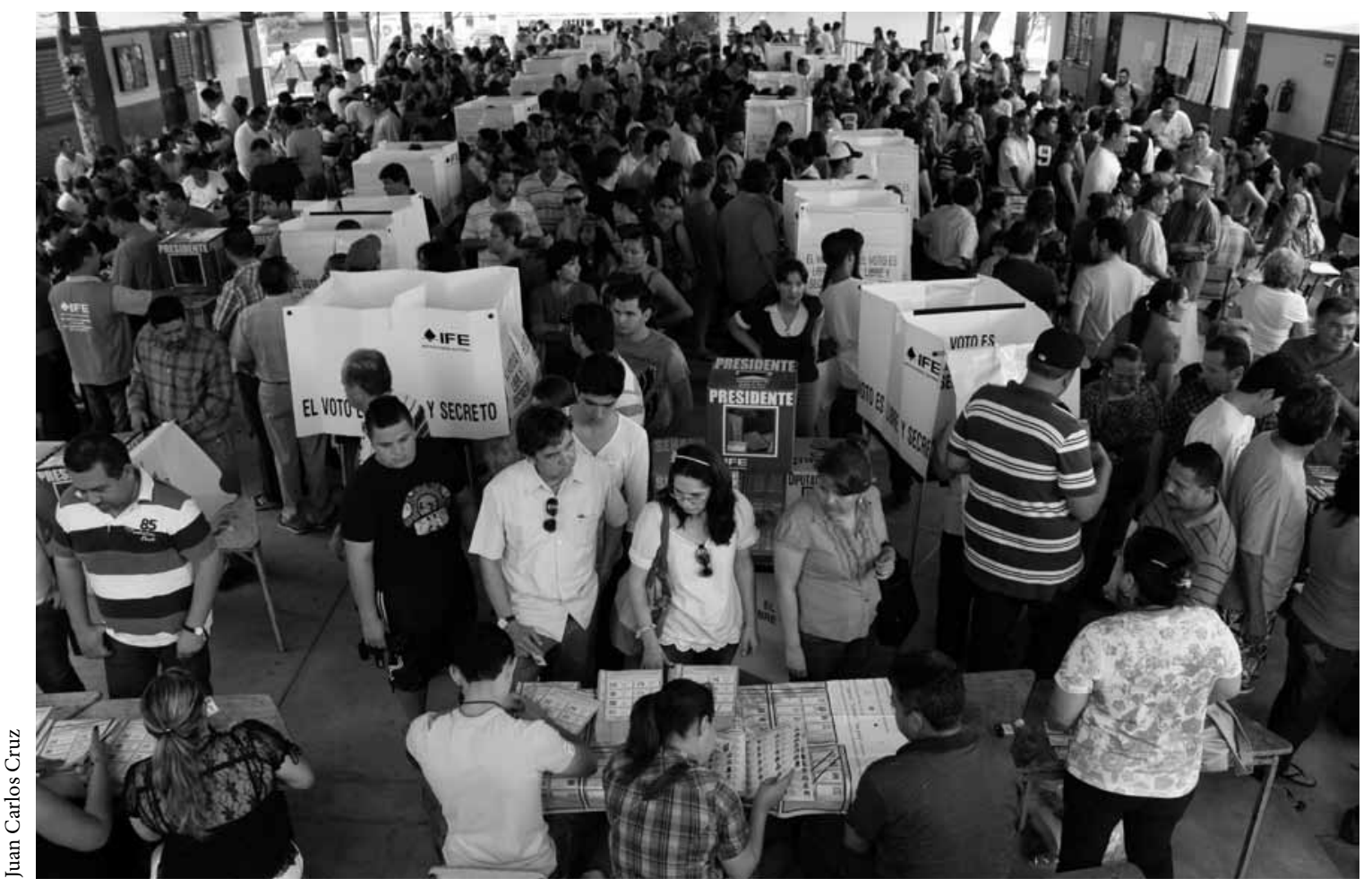

Jornada electoral, 2012. 
de interpretación nacional. El Caribe es ese tercer espacio que el caribeño Wilson Harris ha definido de manera brillante como una dimensión de encuentro de culturas donde el diferente, fragmentado, invisible, puede ser llevado hasta la superficie, mediante una acción consecuente contra los estereotipos y las distorsiones de los discursos, de las metáforas y las configuraciones construidas en la dominación colonial y en la racialización identitaria nacional.

Las diferencias regionales en Brasil dieron matices al tratamiento del negro. Durante los últimos años del siglo XIX, después de instaurada la República, fueron apareciendo las profundas contradicciones de la sociedad brasileña, que comenzaron a hacerse más visibles a partir del peso demográfico del negro. Éste disminuyó en el Sudeste y en el Sur con la entrada de miles de inmigrantes europeos y japoneses atraídos por una burguesía empresarial emergente, por el lucro de la explotación del trabajo esclavo de los negros en las grandes haciendas de café. Mientras tanto, en el Nordeste y en el Norte se garantizó la permanencia de una oligarquía vinculada a la tierra y también las grandes poblaciones negras. En ambas regiones la actitud más frecuente de los exesclavos, sin derecho a la tierra, fue la emigración a las ciudades o el confinamiento en pequeños espacios. La representación del país que se creó entre las elites estuvo presidida por el binomio nación/raza y dejó fuera al negro. De ahí la urgencia de la inmigración blanca europea, principalmente de italianos y alemanes. La construcción de identidades durante el siglo xIX, y aún en los primeros años del siglo $\mathrm{xx}$, estuvo relacionada con ese interés en la marginalización y en el ocultamiento del no blanco.

En las investigaciones pioneras sobre los negros, éstos son todavía percibidos como ajenos a la sociedad brasileña - la raza quedó vinculada a la idea de la africanidad-, y estos especialistas fueron criticados por iniciar esos estudios considerados negativos e inútiles. Para muchos de los intelectuales de la época los negros debían permanecer en la esfera de lo no dicho. Por eso la exclusión del negro de carne y hueso de la historia, estudiada principalmente a partir de efemérides en cuyas celebraciones éste estaba ausente. Así, entre lo no dicho y lo dicho, en el análisis de expresiones sueltas, de fragmentos, y sobre todo en la revisión del debate conceptual del periodo, reflejo de las luchas por espacios políticos, pueden encontrarse algunos aspectos de la historia y de la cultura de los inmigrantes forzados y sus descendientes. De hecho, las fuerzas sociales y políticas que trabajaban en la construcción de una nación "homogénea" blanca mantenían su vista fija en la población negra. Las tensiones con los conceptos, aun entre científicos de la época, muestra el interés por confinar al negro. Éste representaba la diferencia, el "otro" apenas mencionado. Esta historia ha permanecido oscurecida por el predominio de los enfoques subordinados a las teorías jerárquicas occidentales en las ciencias sociales que se acomodaron a las construcciones de identidades forjadas por las elites brasileñas.

La Revista tendría que buscar su espacio y todo parecía indicar que el cambio sería a Río de Janeiro en 2008. Había un ambiente académico favorable, una figura que podría ser la cabeza de la Revista con un buen equipo, el apoyo financiero de la universidad que se interesaba en el tema, cuestiones que no eran resueltas en Goiás, donde el respaldo financiero procedía de los eventos internacionales y el trabajo de diagramación y diseño artístico era de los estudiantes voluntarios. Esas actitudes y políticas están relacionadas con las diferencias regionales. Río de Janeiro podía ser el espacio ideal, pero no fue posible su establecimiento ahí, por lo que se pensó en el Nordeste brasileño. Primero se consideró Bahía, pero el proyecto no se concretó por las graves contradicciones internas que se evidenciaron durante el $V I$ Simposio Internacional, no sólo de 
índole conceptual. La posibilidad de San Luis, región con una tradición en los estudios caribeños y una íntima relación con la Revista desde su nacimiento, se transformó en realidad con el traslado de Isabel Ibarra, actual directora de la Revista. En San Luis existe el contexto que justifica la presencia de la Revista Brasileira do Caribe. Es una isla que se reconoce popularmente como caribeña: el Caribe no está ausente, está presente en la música, en los performances, en la danza, en la sensibilidad que aflora en el simple contacto con las personas en las calles. Aún no puede decirse que está presente en la Universidad, faltan esfuerzos colectivos, pero apenas de los 10 que permaneció en Goiás. Por lo menos aquí los estudiosos de las culturas negras han penetrado en los vínculos y conexiones con el Caribe.

\section{JUSTIFICACIÓN TEÓRICA DE LA REVISTA}

La hipótesis de trabajo en el Cecab y en la Revista Brasileira do Caribe ha sido el estudio de la relación entre la carencia de informaciones sobre el Caribe y el silencio enraizado sobre el negro al interior de Brasil. Un camino interesante fue el análisis de la relación entre las teorías caribeñas y las investigaciones sobre el negro realizadas en el

Caribe y en Brasil. Otro camino procede del estudio y la comparación de las relaciones interraciales en Brasil y el Caribe. En oposición a las experiencias de vínculos interraciales se gestaron las teorías de manera diferente a la práctica cotidiana, pero sin las relaciones entre ambas esferas no se entiende la permanencia de estereotipos que sirvieron de base a la discriminación del negro. Sin embargo, no pueden negarse las especificidades de contextos históricos en los cuales la identidad étnica es apenas una de las facetas de las múltiples identidades que asumen los individuos y los grupos en su proyección política: identidades de clase, de género, de generación, de actividad profesional.

La propuesta de la Revista Brasileira do Caribe tenía que responder a todas esas expectativas, con una visión inter y transdisciplinaria, y considerar las inestables fronteras entre las disciplinas, el estudio en proceso, percepción privilegiada para penetrar en la conexión entre los mundos de hombres y mujeres que sufrieron la desdicha genealógica (Lavou, 2005), la desterritorialización (Deleuze, citado en Glissant, 1990) o el abismo y la posterior reterritorialización como esclavos - $\mathrm{o}$ en los actuales movimientos de los caribeños a sus antiguas metrópolis-. En el proceso, estos hombres y mujeres fueron despojados de la libertad y del apellido que los vinculaba a sus antepasados, a su familia, a la comunidad territorial. Apenas contaron con una memoria de fragmentos, de "restos" (Porto, 2006), para recrear la cultura en la relación con otras lenguas, costumbres, prácticas, experiencias y, sobre todo, en las tensiones provocadas por las condiciones de la esclavitud y más tarde de la discriminación. Así, destituido de sus bienes simbólicos y materiales, el "migrante desnudo" (Glissant, 1999) creó estrategias de sobrevivencia en el seno de las "colectividades nuevas" de Bouchard (citado en Porto, 2007), a través de las "artes de hacer" (De Certeau, 2007) responsables de la invención del cotidiano. La interpretación de estas culturas en América osciló entre las visiones de la jerarquía occidental: las culturas afroamericanas o afroatlánticas como el límite de Occidente - Van Lier, Keller y el pensamiento imperial en general- o las búsquedas de identidades transnacionales que transitaron entre la poética y el historicismo (Paget, 2000), hasta el reciente encuentro de estas tendencias en la filosofía caribeña, cuyos exponentes son también grandes literatos: Walkott, Glissant, Harris, sin olvidar a Carpentier y García Márquez, entre otros. En este sentido, los escritores 
poscoloniales, por medio de propuestas filosóficas alternativas a la marginalización de la historia y sus construcciones metonímicas, criticaron los paradigmas excluyentes de la modernidad, y sus trabajos desembocaron en los estudios culturales como forma de alcanzar una mejor comprensión de la realidad.

La Revista Brasileira do Caribe tiene como eje fundamental el estudio de la relación, el entrecruzamiento o, como otros autores denominan, las conexiones, en un acercamiento interdisciplinar que suscita una forma de construcción del propio objeto de estudio. Esos conceptos aluden a la tentativa de huir de la óptica restringida a la comprensión de los fenómenos sociales, políticos y culturales en su aislamiento y bajo los modelos de una disciplina maestra. En esta línea, la Revista Brasileira do Caribe está orientada por la idea de la relación del Caribe con los estudios sobre Brasil, por el énfasis en la búsqueda de los vínculos y conexiones entre los acontecimientos y las disciplinas. No se trata de estudios comparativos en los que el eje del análisis es la perspectiva próxima, sujetos a la interpretación regionalista y/o a las visiones esencialistas que se pretenden trascendentes. Brasil y el Caribe, al ser transformados en lugares de recepción de millones de esclavos traídos por los europeos desde África, se construyeron como culturas, principalmente en la articulación entre la herencia dejada por la idea europea de progreso y las matrices culturales negras en ese tercer espacio (Harris, 1999) de conexión, de negociación, de hibridismo cultural. Sobre la relevancia de esas conexiones, el cubano Benítez afirma:

Si el periodo particular de la historia de la humanidad viniese a ser caracterizado de manera simple, podría ser uno en el cual el mundo está conectado más intensamente, más globalmente y al mismo tiempo más inesperadamente que en cualquier época del pasado. Y si esta época, que llamo "época conectada", debe ser comprendida, debemos aprender primero cómo se puede describir científicamente; esto es, necesitamos una ciencia que estudie las redes de conexiones (Benítez, 2004: 13-14).

El autor explica que la época conectada no puede ser estudiada a partir de un modelo y menos aun mediante una disciplina específica, sino por medio de las relaciones entre disciplinas. Insiste en que el examen de las conexiones ofrece mejores resultados que aquellos obtenidos cuando se estudia un sistema separado. Podemos afirmar que las conexiones no simplemente están en la compleja realidad, sino también en un análisis interdisciplinario. En la búsqueda del diferente omitido u oculto no es suficiente la utilización del método crítico clásico de la Historia, por lo que se echa mano de otras fuentes, de otras perspectivas. Pueden configurarse formas alternativas de interpretar el mundo desde las matrices filosóficas afroamericanas, sustentadas en las obras literarias y ensayísticas de varios autores. Las relaciones entre disciplinas proceden asimismo del interés en el estudio de los fragmentos, de las márgenes. El lugar de la enunciación es el de la distorsión, el de la secuencia real de los acontecimientos que se presentan configurados y resignificados por las ideologías dominantes (Guha, 1999). Son los fragmentos descontextualizados expresivos de las tensiones los que ganan importancia para las ciencias humanas. Observar lo caribeño dentro de los contextos afroatlánticos, en la conexión, conduce a un conocimiento del Caribe más profundo. En referencia a ese aspecto, Glissant (1990) enuncia su Poética de la relación. La conexión afroatlántica, por otra parte, confronta los discursos más agresivos de la globalización y ofrece posibilidades de resistencia global que no deben subestimarse.

Además de los vínculos entre disciplinas, en la búsqueda de un enunciado general de la Revista Brasileira do Caribe fue 


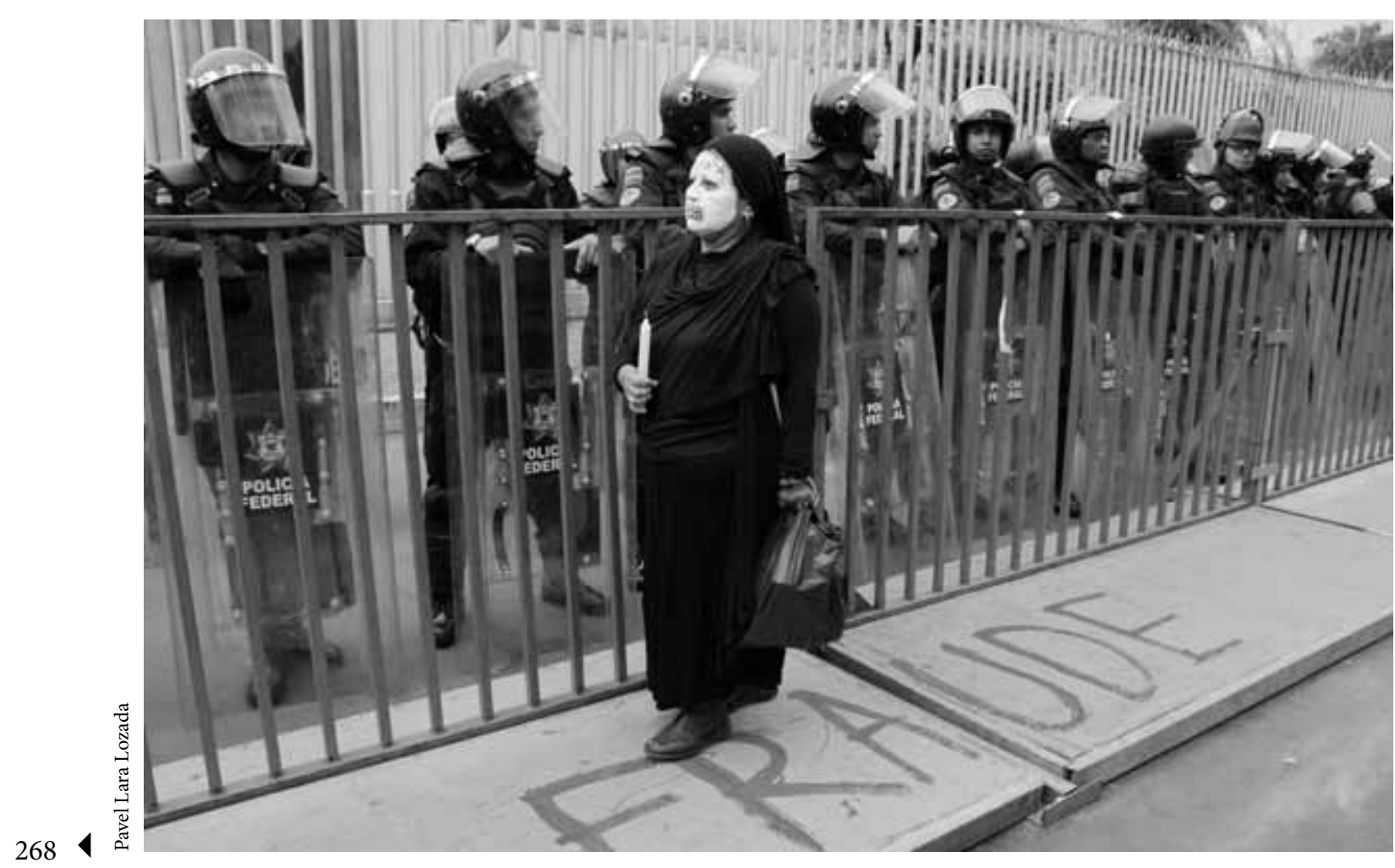

Diversas formas de manifestación se hacen presentes frente al Tribunal Electoral del Poder Judicial de la Federación, 2012.

importante la elaboración de un proyecto intelectual, teóricamente basado en la comprensión de que la ausencia de los estudios caribeños en Brasil revela la visión teórica de las ciencias sociales y humanas. La relación Brasil-Caribe enfrenta los vacíos en la historiografía y en la vida académica brasileñas. En Brasil no son estudiadas las relaciones y conexiones con el Caribe, a pesar de las evidencias de elementos comunes. El Caribe es apenas la dimensión geopolítica que el pensamiento imperial le atribuyó. El Caribe supone un debate intelectual para los estudios afroamericanos, cuyo espacio de reflexión siempre ha sido transnacional y constituye una filosofía alternativa que permite pensar las culturas negras en la actualidad. La no historia ha impuesto una comprensión de Brasil en los límites diacrónicos de las efemérides nacionales que desconoce la simultaneidad de tiempo y de lugares: en los siglos xv y xvi el Atlántico se transformó en el escenario principal de contactos desiguales entre pueblos de África, América y Europa, lo que provocó una dinámica interna, ora por los desplazamientos migratorios forzados, ora por el desigual desarrollo tecnológico. Las interconexiones culturales y políticas entre el Caribe, Brasil y África, por tanto, son resultantes de un pasado colonial común y de las relaciones mantenidas entre esas regiones en el actual proceso de globalización. De ese modo, estudiar el Caribe en Brasil exige analizar sus interconexiones atlánticas, lo que significa reaccionar contra las nociones de centro y periferia, de las identidades estáticas, de las culturas monolíticas fijas en la tradición, de las fronteras como límites y no como intersticios abiertos a la negociación y al diálogo intercultural, mas también al debate y a las tensiones como el 
respeto a la diversidad cultural.

Las definiciones externas del Caribe impuestas por el poder colonial tienen que ser cuestionadas desde dentro. Para entenderse a sí mismo, Brasil ha de trascender la visión nacionalista de búsqueda de la valorización a partir de los orígenes y penetrar en los procesos de formación histórica, social, política y cultural ocurridos en el Caribe con la migración forzada del "migrante desnudo". Lo que "realmente" ocurrió tanto en el Caribe como en Brasil pertenece a la "no historia", son los "restos" dejados por los interlocutores silenciados, protagonistas que, arrancados de sus tierras africanas y aún forzados y sometidos a la esclavitud, configuraron otra forma de percibir e interpretar el mundo. Comprender las diversas fuerzas que han participado en la formación de Brasil y del Caribe significa también estudiar en la lengua impuesta la negociación con el otro, además de la incorporación de otras fuentes, como la danza, la música, la oralidad. El diálogo, "la relación poética" (Glissant, 1990), entre Brasil y el Caribe es intenso. Si la literatura, la música, la cultura y la historia caribeñas han llegado a Brasil, también el Caribe tiene que aprender de la literatura, la cultura, el cine, la música brasileñas, con Guimarães Rosa, Euclides da Cunha y Glauber Rocha, entre otros. Después de
25 números, la Revista Brasileira

do Caribe, sus gestores y

colaboradores están más que nunca comprometidos en esa tarea histórica. Cuando el sertón brasileño, como pronosticaba Guimarães Rosa, llegue a ser mar será el momento en que su estudio haya ganado terreno entre los historiadores y entonces sí el estudio del Caribe será una exigencia. Entonces serán definitivamente vencidos el sertón del desarrollismo, el sertón de la modernidad y el sertón de las elites. Llegará a ser mar en la "época de oro" de la historia que, nutrida por las experiencias de sus agentes apagados, revivirá el sertón negro, ausente de la academia y sólo entrevisto como singular, folclórico y marginal a la historia principal.

\section{BIBLIOGRAFÍA}

Appiah, Kwame Anthony, 1997, Na casa de meu pai: a África na filosofia da cultura, Contraponto, Río de Janeiro.

Bhabha, Homi, 1998, O local da cultura, Editora Universidade Federal de Minas Gerais, Belo Horizonte.

Benítez Rojo, Antonio, 2004, "El Caribe y la conexão afro Atlântica", en Olga Cabrera y Jaime de Almeida (orgs.), Caribe: sintonias e dissonâncias, Centro de Estudos do Caribe no Brasil, Goiânia.

Bernd, Zilá y Maria do Carmo Campos (orgs.), 1994, Literatura e americanidade, Editora da Universidade Federal do Rio Grande do Sul, Porto Alegre.
Bernd, Zilá et al., 1998, Escrituras híbridas: estudos em literatura comparada interamericana, Editora da Universidade Federal do Rio Grande do Sul, Porto Alegre.

Bernabé, Jean et al., 1989, Éloge de la créolité, Gallimard, París.

Bosi, Alfredo, 1993, Dialética da colonização, Companhia das Letras, São Paulo.

Cabrera, Olga, 2000, "Introdução", en Anais do I Simpósio Internacional do Centro de Estudos do Caribe no Brasil "Entre Experiências e Sentidos. Caribe: Etnia e Região", Centro de Estudos do Caribe no Brasil, Goiânia.

—_, 2002, "Introdução", en Anais do II Simpósio Internacional do Centro de Estudos do Caribe no Brasil "Fronteiras, Migrações e Cultura", Centro de Estudos do Caribe no Brasil, Goiânia. 2003, "A literatura e a filosofia da contracultura caribenha em Alejo Carpentier", en Jaime de Almeida, Olga Cabrera, María Teresa Cortés Zavala y Cléria Botêlho da Costa (orgs.), Cenários Caribenhos, Paralelo 15, Brasilia. , 2004a, "Entre a invisibilidade e a cor do medo. Literatura e escravidão no Brasil e em Cuba", en Olga Cabrera y Jaime de Almeida (orgs.), Caribe: sintonias e dissonâncias, Centro de Estudos do Caribe no Brasil, Goiânia.

— 2004b, "Introdução", en

Anais do III Simpósio Internacional do Centro de Estudos do Caribe no Brasil "Culturas híbridas no Atlântico: Relações África-Ásia-BrasilCaribe", Centro de Estudos do Caribe no Brasil, Goiânia. , 2006, "Introdução", en Anais do IV Simpósio Internacional do Centro de Estudos do Caribe no 
Brasil "Migrações e Processos Identitários: África-Brasil-Caribe", Centro de Estudos do Caribe no Brasil, Goiânia.

—, 2008, "Introdução", en Anais do V Simpósio Internacional do Centro de Estudos do Caribe no Brasil "Fronteiras e Culturas em Movimento: África, Brasil Caribe”, Centro de Estudos do Caribe no Brasil, Goiânia.

Carpentier, Alejo, 1949, El reino de este mundo, Siglo XXI, México. 1969, Los pasos perdidos, Unión, La Habana. , 1974, El siglo de las luces, Letras Cubanas, La Habana.

— 1979, La música en Cuba, Letras Cubanas, La Habana. -, 1983, Ecué Yamba-Ó, Siglo XXI, México. , 1994, Temas de la lira y el bongó, Letras Cubanas, La Habana.

Césaire, Aimé, 1943, Retorno al país natal, Ediciones Molina y Compañía, La Habana.

Chamoiseau, Patrick, 1997, Écrire en pays dominé, Gallimard, París.

— y Raphaël Confiant, 1991, Lettres créoles: tracées antillaises et continentales de la littérature, Hatier, París.

Damato, Diva B., 1996, Édouard Glissant: poética e política, Annablume, São Paulo.

De Certeau, Michel, 2007, El lugar del otro, Katz, Buenos Aires.
Depestre, René, 1980, Bonjour et adieu à la negritude, Robert Laffont, París.

Des Rosiers, Joël, 1996, Théories caraïbes: poétiques $d u$ déracinement, Tryptique, Montreal.

Fanon, Frantz, 1952, Peau noire masques blancs, Seuil, París.

Figueiredo, Eurídice, 1998, Construções de identidades pós-coloniais na literatura antilhana, Editora Universidade Federal Fluminense, Niterói.

Gilroy, Paul, 2001, O Atlântico negro: modernidade e dupla consciência, Editora 34, São Paulo.

Glissant, Édouard, 1981, Le discours antillais, Seuil, París. , 1990, Poétique de la Relation, Seuil, París. -, 1995, Introduction à une poétique du divers, Les Presses de l'Université de Montréal, Montreal.

— 1999, Caribbean Discourse. Selected Essays, Virginia University Press, Charlottesville.

Guha, Ranajit, 1999, "La muerte de Chandra”, en Historia y Grafía, núm. 12.

Guimarães Rosa, João, 1956, Grande sertão veredas, Livraria Jose Olympio, Río de Janeiro.

Hall, Stuart, 2003, Da diáspora: identidades e mediações culturais, Editora Universidad Federal de Minas Gerais, Organización de las
Naciones Unidas para la Educación, la Ciencia y la Cultura, Belo Horizonte, Brasilia.

Harris, Wilson, 1999, Select Essays of Wilson Harris, Routledge, Londres y Nueva York.

Lavou Zoungbo, Victorien, 2005, “De la desdicha genealógica al espacio genealógico: la revolución del ser del migrante desnudo en el Caribe", en Revista Brasileira do Caribe, vol. 5, núm, 10, pp. 263-280.

Mianpika, Landry Walfrid, 2005, Transculturación y poscolonialismo en el Caribe. Versiones y subversiones de Alejo Carpentier, Verbum, Madrid.

Ortiz, Fernando, 1983, Contrapunteo del tabaco y del azúcar, Editorial de Ciencias Sociales, La Habana.

Paget, Henry, 2000, Calibans Reason: Introducing Afro-Caribbean Philosophy, Routledge, Londres y Nueva York.

Porto, Maria Bernadette, 2006, "Paisagens de insularidade: a poética do exíguo na literatura antilhana de língua francesa", en Revista Brasileira do Caribe, vol. VI, núm. 12. , 2007, "Uma voz da diaspora haitiana na literatura migrante do Quebec", en Revista Brasileira do Caribe, vol. VIII, núm. 15, pp. 109-136. 